\title{
Marking planes of surgical excision on breast biopsy specimens: use of artists' pigments suspended in
} acetone

\author{
D A PATERSON, J D DAVIES University Department of Pathology, Bristol Royal Infirmary, Bristol
}

SUMMARY The performance of carbon and metallic inks, silver nitrate solution, and artists' pigments mounted in acetone was compared for marking the surface of surgical biopsy specimens. Using India ink is an unsatisfactory procedure because of slow drying, messiness, and spreading of the ink. It is concluded that use of artists' pigments has many advantages over other reagents, because of their rapid drying, resistance to tissue processing, and the ability to mark simultaneously many different planes of excision. Furthermore, the pigments are readily visible, are distinguishable from each other on microscopical examination, and the method entails little extra cost.

In routine histopathological practice the assessment of the adequacy of excision of lesions requires identification and clear marking of the margins of surgical excision. Traditionally, this has been achieved by the use of India ink, or by cutting a notch opposite the plane of excision in the specimen block. ${ }^{2}$ Both these methods carry disadvantages: India ink is slow to dry, spreads over the surface of the specimen, and is consequently very messy; notching may possibly lose diagnostic tissue from the core of the excised tissue. It is also generally acknowledged that both these methods of marking the planes of surgical excision are notoriously prone to error. ${ }^{3}$

We attempted to improve on these long standing methods, and simultaneously to extend the range of markers, such that multiple margins of excision can be identified on a single block of tissue. For this purpose we assessed the performance and relative costs of applying three particulate inks, a silver salt, and six artists' pigments ${ }^{4}$ in acetone to the external surfaces of routine surgical breast biopsy specimens.

\section{Material and methods}

A consecutive series of 74 surgical breast specimens received in the department of pathology at this hospital between October 1986 and August 1987 was studied. All the specimens were fixed at least overnight in $10 \%$ unbuffered but freshly prepared formol saline,

Accepted for publication 7 April 1988 and then were carefully dried with a paper towel before the marking inks and pigments were applied to their external surfaces with a size 101 hair paint brush. Additional drying in the air at this stage is unnecessary.

The following four inks or inorganic silver-salt markers were used: India ink (Rotring, West Germany; consisting of a colloidal suspension of particulate carbon in aqueous gum); silver ink (Winsor and Newton, Harrow; a colloidal suspension of particulate zinc metal in gum); gold ink (Winsor and Newton, Harrow; a colloidal suspension of particulate bronze in gum); and a $10 \%$ solution of silver nitrategeneral purpose grade - in methanol.

In addition, dry fine ground powdered artists' grade pigments (Winsor and Newton, Harrow), suitable for water colour, oil, or gouache work were freshly mounted, using latex gloves and a standard formalinfume extractor, as a suspension in acetone at about $50 \% \mathrm{w} / \mathrm{v}$ to yield a thin paste capable of application by a watercolour-type paint brush to the specimens.

Many pigments were assessed; but white pigments with crystals which appeared black in transmitted light on microscopy were not considered further. Those used in the main study were the following six pigments, which had proved on a trial basis to be the most satisfactory-namely, cobalt blue-its alternative names include cobalt blue light or deep (chemically, cobalt aluminate); alizarin crimson-also known as crimson lake or rose madder alizarin (1:2 dihydroxyanthraquinone); viridian-sometimes called green 
oxide or chromium - (hydrated chromium sesquioxide); cadmium red (a mixture comprising cadmium sulphide, cadmium selenide, and barium sulphate); Venetian red-also known as red ochre or English red-(ferric oxide); and permanent mauve-also called manganese violet-(manganese ammonium pyrophosphate). These pigments, with yet more alternative names ${ }^{4}$ to those cited above are also sold under these other names by many retailers in this field.

After painting the external surfaces the specimens were allowed to dry for the necessary periods of between 15 and 30 minutes (table) in the ambient air. Blocks of tissue for histological examination were then taken to assess the efficacy of marking of the planes of surgical excision. These selected blocks were processed in the routine manner in our laboratory, using graduated ethanols and toluene, ${ }^{5}$ sectioned, rehydrated, and thereafter cleared using ethanol and xylene, and were then examined by light microscopy after staining with Harris's haematoxylin and eosin. At first, about equal numbers of cases were submitted to the various marking substances. In the latter part of the study more than one of the coloured artists' pigments, mounted in acetone as described above, was applied to an individual specimen.

\section{Results}

The 10 different markers assessed all possessed their own peculiar characteristics. All the three carbon and metallic inks yielded an easily visible pigmentation after application. Silver nitrate, however, is macroscopically invisible at the concentration of $10 \%$ used. India ink was the slowest to dry, and like silver nitrate, had a tendency to spread beyond the edge of the area marked (table). During processing there was a loss of some of the metallic silver and gold inks - severe in a few instances-whereas both India ink and silver nitrate were well retained and readily visible on microscopy all over the marked margins of the blocks painted with them. On microscopy, all the three inks were a black colour and the silver nitrate gave a brown coloured edge to the blocks. The India ink led to a black line which on low and medium magnification was apparently homogeneous. The other two inks, and the brownish freshly precipitated salt (most probably $\mathrm{AgCl}_{2}$ ) from the silver nitrate solution, microscopically comprised larger particles.

Applied as a thin and workable paste in acetone, the six artists' pigments carried several important advantages over the inks and silver nitrate. Firstly, they were quick to dry, taking less than 15 minutes, as opposed to the full half hour required with India ink. Drying time for all the markers can be shortened by blotting with tissue paper, but such blotting after application of the pigments led to loss of some pigment, and was therefore abandoned. None the less there was a considerable time saving with this simple method of drying, which takes over 30 minutes with unblotted India ink, hence its reputation for messiness.

Macroscopically the colours were readily visible, and with the exception of two of the red pigments (cadmium and Venetian red) and permanent mauve, were easily distinguishable from one another at microscopy in direct light. Importantly, they also showed little tendency to spread over the surface of the specimen, and they were all well preserved during the tissue processing. Furthermore, none of the artists' pigments displayed the tendency of India ink to permeate deeply between the adipose lobules of the breast tissue.

On microscopy, cobalt blue, viridian, and alizarin crimson were seen as distinctive blue, green, and red crystals, respectively (fig 1). Microscopically, cadmium red, Venetian red, and permanent mauve all appeared black in ordinary illumination, but were distinguishable from each other, respectively, as red, black, and purple crystals when viewed in polarised light (fig 2).

The optical and other properties of the 10 markers

Table Functional properties of three marking inks, silver nitrate, and six artists' pigments

\begin{tabular}{|c|c|c|c|c|c|}
\hline \multirow[b]{2}{*}{ Marker } & \multicolumn{2}{|l|}{ Colour } & \multirow{2}{*}{$\begin{array}{l}\text { Resistance } \\
\text { to processing }\end{array}$} & \multirow[b]{2}{*}{ Spreading } & \multirow[b]{2}{*}{ Time taken to dry } \\
\hline & Macroscopic & Microscopic & & & \\
\hline $\begin{array}{l}\text { India ink } \\
\text { Gold ink } \\
\text { Silver ink } \\
\text { Silver nitrate } \\
\text { Cobalt blue } \\
\text { Viridian } \\
\text { Alizarin crimson } \\
\text { Cadmium red } \\
\text { Venetian red } \\
\text { Permanent mauve }\end{array}$ & $\begin{array}{l}\text { Black } \\
\text { Gold } \\
\text { Silver } \\
\text { Invisible } \\
\text { Blue } \\
\text { Green } \\
\text { Crimson } \\
\text { Bright red } \\
\text { Dull red } \\
\text { Purple }\end{array}$ & $\begin{array}{l}\text { Black } \\
\text { Black } \\
\text { Black } \\
\text { Brown } \\
\text { Blue } \\
\text { Green } \\
\text { Red } \\
\text { Black } † \\
\text { Black } \\
\text { Black } \ddagger\end{array}$ & $\begin{array}{l}\text { Good } \\
\text { Poor } \\
\text { Poor } \\
\text { Good } \\
\text { Good } \\
\text { Good } \\
\text { Good } \\
\text { Good } \\
\text { Good } \\
\text { Good }\end{array}$ & $\begin{array}{l}\text { Yes } \\
\text { No } \\
\text { No } \\
\text { Yes } \\
\text { No } \\
\text { No } \\
\text { No } \\
\text { No } \\
\text { No } \\
\text { No }\end{array}$ & $\begin{array}{l}\text { Slow } \\
\text { Quick } \\
\text { Quick } \\
\text { Quick } \\
\text { Quick } \\
\text { Quick } \\
\text { Quick } \\
\text { Quick } \\
\text { Quick } \\
\text { Quick }\end{array}$ \\
\hline
\end{tabular}

*Slow $\simeq 30$ minutes; quick $\leqslant 15$ minutes.

tRed in polarised light.

$\ddagger$ Purple in polarised light. 


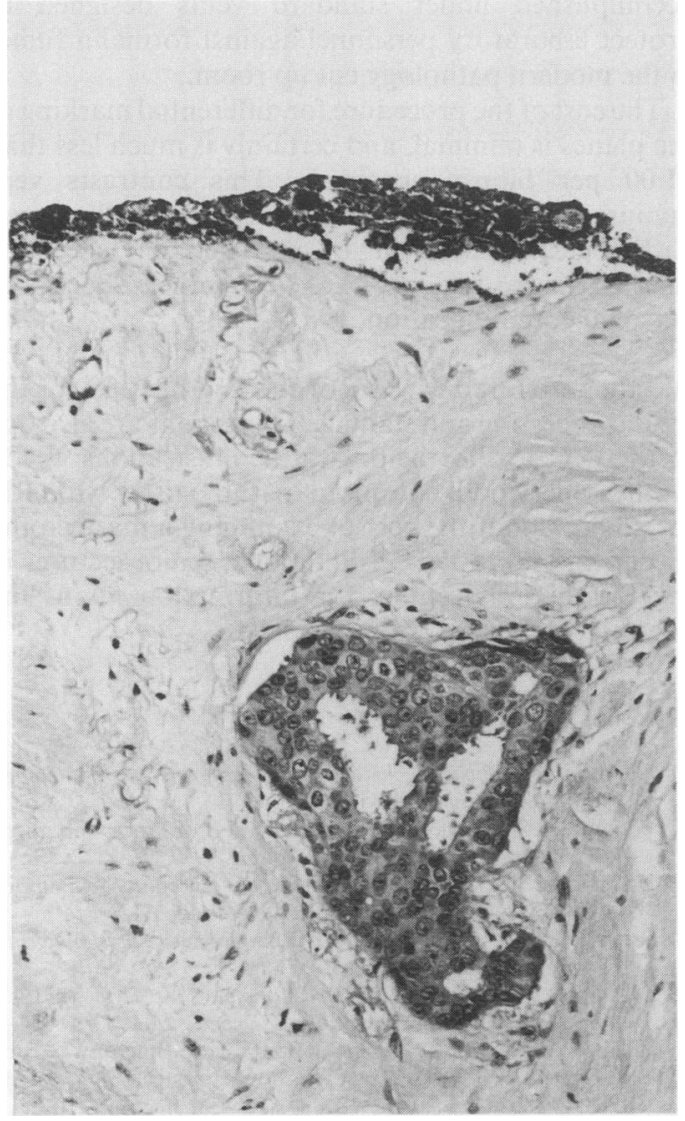

Fig 1 Crystals of alizarin crimson on surface of breast biopsy specimen containing a ductal carcinoma. (Haematoxylin and eosin.)

used in this study are summarised in the table.

Current retail prices for small quantities of the reagents, with up to $30 \mathrm{ml}$ units of artist-standard pigments have been costed per $2 \mathrm{ml}$ of the working suspensions - which was more than adequate to cover one entire plane surface of the surgical breast biopsy specimens. For the 10 markers studied, the costings, in ascending order were: India ink $5 \mathrm{p}$; silver ink $6 \mathrm{p}$; gold ink $6 \mathrm{p}$; alizarin crimson $6 \mathrm{p}$; Venetian red $6 \mathrm{p}$; silver nitrate 9p; permanent mauve $10 \mathrm{p}$; viridian $15 \mathrm{p}$; cobalt blue $15 \mathrm{p}$; cadmium red $15 \mathrm{p}$.

\section{Discussion}

In the treatment of the earlier forms of breast cancer simple mastectomy, or tylectomy is tending to supercede radical resection. ${ }^{2}$ These more conservative operations are often combined with cosmetic procedures and external radiotherapy or local implants. ${ }^{67}$

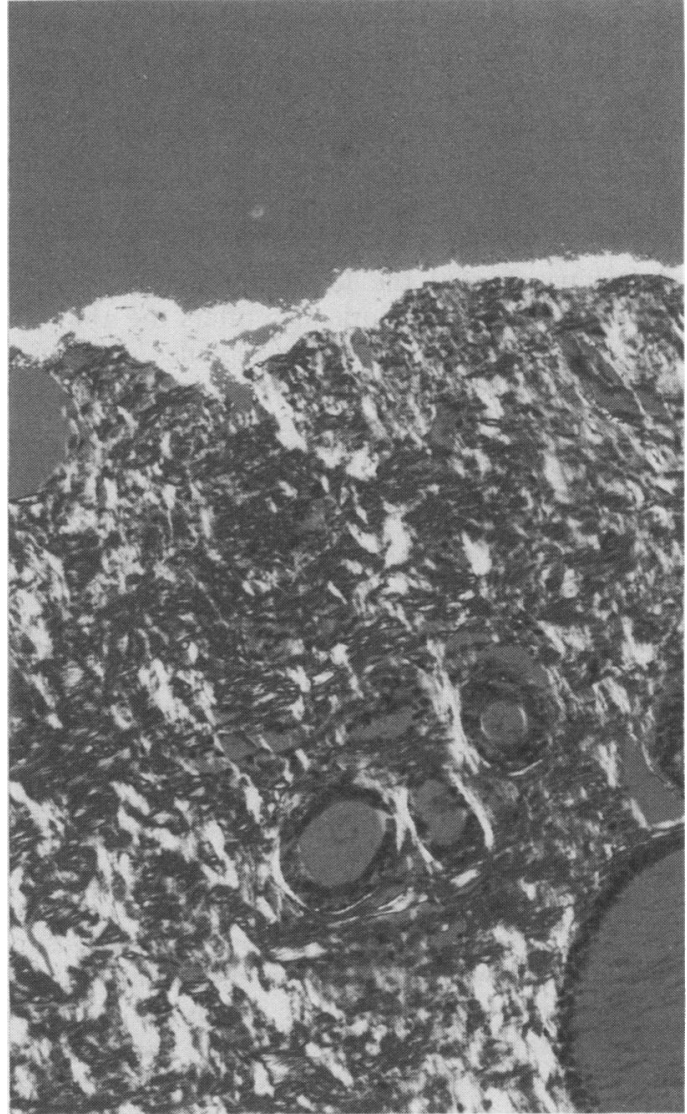

Fig 2 Anisotropic crystals of cadmium red, which appear red on polarisation, and bifringent collagen fibres in biopsy specimen of fibrocystic disease (polarised light). (Haematoxylin and eosin.)

With such departures from radical surgical resection, there is an increasing need for accurate pathological identification of the precise planes of surgical excision which are closest to the tumour. Only in this way can any further rational local treatment be planned.

There are considerable disadvantages to the usual pathological methods of marking a plane of surgical resection with ink or by notching. Unless preliminary drying of the specimen has been scrupulous, and fully adequate time given for subsequent drying, marking with India ink can be a very messy procedure. Furthermore, there are considerable difficulties in distinguishing microscopically between the metallic inks and silver nitrate. In sum, these methods are poorly adapted to differential marking of different planes of surgical excision.

Using the traditional techniques for the preparation of artists' paints, insoluble pigments are finely ground and then mounted in slow drying oil-based or aqueous 
media. The pigments are mostly inorganic, but nowadays, include some organic compounds.

We believe that the use of the same artists' pigments, suspended in the rapidly volatile mountant acetone, circumvents almost all the difficulties experienced in pathology with the gum-mounted carbon and metallic inks or aqueous silver nitrate when marking fixed surgical specimens. Preliminary investigations ${ }^{8}$ with cobalt blue showed the feasibility of the method. Furthermore, the technique also offers the ability to distinguish with ease at least six planes of surgical excision. These planes are unlikely to become confused either macroscopically as the pigments in their acetone mountant do not spread, and they all dry relatively quickly. The very volatility of acetone, however, requires that the suspensions are used within a few days of preparation. At present the possible application of the method to unfixed breast tissue - which is nowadays often received for complementary investigations ${ }^{2}$-remains to be ascertained.

All the six chosen artists' pigments are easily visible macroscopically and have proved, unlike the metallic silver and gold inks, to be resistant to standard histological tissue processing and further treatment of sections in the organic solvents ethanol, toluene, and xylene. Cobalt blue, alizarin crimson, and viridian are, respectively, blue, red, and green macroscopically and retain the same colours on microscopy. With the use of polarising microscopy, cadmium red, Venetian red, and permanent mauve-which all appear as black crystals in unpolarised light - can also be separated from one another. In this way a colour coding system for the six medial, lateral, inferior, superior, deep and superficial planes is readily devised.

Despite the insolubility of the traditional artists' pigments ${ }^{4}$ in appropriate media, especial care ${ }^{4}$ needs to be taken, especially with the dry and powdered form of the manganese, ${ }^{4}$ cobalt, ${ }^{9}$ and cadmium ${ }^{10}$ pigments. Use of gloves, an extraction apparatus, and possibly a paper face mask at this stage are wise precautions. Once in suspension with acetone, however, there is unlikely to be any problem with the potential toxicity of the cations of these pigments during the subsequent processing or staining. The evaporation of the acetone from the surface of the specimen can be safely accomplished under standard vents designed to protect laboratory personnel against formalin fumes in the modern pathology cut up room.

The cost of the procedure for differential marking of the planes is minimal, and certainly is much less than $£ 1.00$ per biopsy specimen. This contrasts very favourably with an estimate that the full overall pathological assessment ${ }^{2}$ of a mastectomy specimen today is in the region of $\mathbf{6 5 5 . 0 0}$ (Anthea Sherwood, personal communication, 1987).

We are grateful to $\mathrm{Mr} \mathbf{G}$ Roberts and his staff for the tissue processing and staining. Our thanks are also due to $\mathrm{Mr}$ C C Jeal for help with the illustrations; to $\mathrm{Dr}$ Anthea Sherwood, consultant pathologist, Plymouth, for advice about the cost of examining a mastectomy specimen; and to Dr C J Phillpotts, senior lecturer in the Bristol Polytechnic, for information about the potential toxicity of cadmium salts.

References

1 Kennedy A. Basic techniques in diagnostic histopathology. Edinburgh: Churchill-Livingstone, 1977.

2 Bogomoletz WV, Davies JD. Examination of breast specimens. ACP Broadsheet. London: ACP/BMA, 1987.

3 Underwood JCE. Intraduction to biopsy interpretation and surgical pathology. 2nd ed. London: Springer-Verlag, 1987.

4 Saityzk SL. Art hardware: the definitive guide to artists' materials $\mathrm{S}$ New York: Watson-Guptill, 1987:150-99.

5 Davies JD, Young EW, Mera SL, Barnard K. Lysozyme is 6 component of vascular elastic fibres. Experientia 1983;39:382-3.

6 Hellman S, Harris JR, Levene MB. Radiation therapy of early carcinoma of the breast without mastectomy. Cancer 1980;46:988-94.

7 Tobias JS, Peckham MJ. Changing attitudes in the local management of early breast ciancer. In: Tobias JS, Peckham MJ, eds. Primary management of breast cancer. London: Edward Arnold, 1985:41-55.

8 Paterson DA, Davies JO. A cobalt aluminate method of marking resection margins. J Pathol 1987;152:206A-7A.

9 Cottier H. Pathogenese: Ein Handbuch für die ärztliche Fortbildung. Berlin: Springer-Verlag, 1980:1605-7.

10 Friberg L, Elinder CG, Kjellström T, Nordberg GF. Cadmium and health: a toxicological and epidemiological appraisal. Florida: CRC Press, 1985.

Requests for reprints to: Dr JD Davies, University Department of Pathology, Marlborough Street, Bristol Royal Infirmary, Bristol BS2 8HW. 